\title{
A study of Follicle Stimulating Hormone (FSH) and Luteinizing Hormone (LH) in women of Polycystic Ovarian Disease (PCOD) at Tertiary Care Hospital of Gujarat, India
}

\author{
Jigar G Shaherawala1, Prashant M Jadav ${ }^{2, *}$ \\ Assistant Professor, Dept. of Biochemistry, ${ }^{1}$ Smt. NHL Municipal Medical College, Ahmedabad, Gujarat, ${ }^{2}$ GCS \\ Medical College, Ahmedabad, India \\ *Corresponding Author: \\ Email: prashantjadav11111@gmail.com
}

\begin{abstract}
Introduction: Polycystic ovarian disease (PCOS) is one of the most common female endocrine disorders. PCOD produces symptoms in approximately $5 \%$ to $10 \%$ of women of reproductive age (12-45 years old). It is thought to be one of the leading causes of female subfertility.

Objectives: To establish correlation among LH, FSH, fasting blood sugar and lipid profile among the women with polycystic ovary syndrome (PCOS), in order to evaluate their diagnostic and prognostic significance

Materials and Methods: This study includes total 500 female participants of age Group between 18-40 year of age. They were divided in to two groups. Group $1(\mathrm{n}=300)$ includes women having PCOD (Cases Group) and Group 2(n=200) is controls Group. Fasting Blood samples were obtained from all participants to measure Blood sugar, Lipid Profile FSH and LH.

Results: The Mean level of Fasting Blood sugar, Serum cholesterol, Serum Triglyceride, Serum FSH and Serum LH is found to be higher in Cases group as compared to controls group and difference among them found to be statistically significant.

Conclusion: PCOD is a very complicated endocrine disorder. Blood tests to measure hormone levels, an ultrasound to look at your reproductive organs and thorough personal and family histories should be completed before a PCOD diagnosis is confirmed. Assessing hormone levels serves two major purposes. First of all, it helps to rule out any other problems that might be causing the symptoms. Secondly, together with an ultrasound and personal and family histories, it helps gynecologist to diagnose the cases of PCOD.
\end{abstract}

Keywords: FSH, LH, Lipid Profile, PCOD.

Received: $11^{\text {th }}$ September, 2017

\section{Introduction}

Polycystic Ovary Syndrome (PCOD) is a condition that affects women of menstruating age. Although it is not life-threatening, it can be uncomfortable and can cause fertility challenges for some women. Women with polycystic ovary Syndrome (PCOS) can get pregnant, but their risk of pregnancy complications is higher than average. ${ }^{1}$ The polycystic ovary syndrome (PCOS) is a mostly hyper androgenic disorder and is possibly the most common endocrinopathy of premenopausal women. ${ }^{2}$ The primary defect in polycystic ovary syndrome (PCOS) appears to be an exaggerated androgen synthesis (Testosterone) and secretion by the ovaries and the adrenal glands (according to "NIH criteria", 1990)., ${ }^{2,3}$ In a substantial proportion of polycystic ovary syndrome (PCOS) patients, the primary defect in androgen secretion is triggered by factors such as the hyperinsulinism resulting from insulin resistance and/or the secretion of metabolically active substances by visceral adipose tissue, because
Accepted: $05^{\text {th }}$ October, 2017

these factors may facilitate androgen synthesis at the ovaries and the adrenals of predisposed women. ${ }^{2}$

Therefore, the present investigations was carried out to assess LH and FSH hormones level. Subsequently regular assessing of Blood glucose, lipid profile in clinical biochemistry laboratory is important to monitor \& study the effect of these parameters among normal and polycystic ovary Syndrome (PCOS) women \& its adverse consequences.

\section{Materials and Methods}

This prospective study was conducted at Department of Biochemistry and Department of Obstetrics \& Gynaecology, Smt NHL Medical College \& attached V.S general Hospital, Ahmedabad, Gujarat, India from June 2016-July 2017 after obtaining permission of institute Ethical committee.

A total of 500 study subjects of age group between 18-40 years were classified in to 2 groups. 
Group-1: 300 women with PCOD as cases group

Group-2: 200 normal women as a controls group

All PCOD women \& controls were underwent a complete history and physical examination. Women with PCOD were interviewed of their name, address etc. All women were gone through gynaecological ultrasonography to determine their uterus and ovaried condition.

Inclusion criteria: Women with PCOD are attending outdoor OPD of the hospital, first time diagnosed PCOD, Diagnosed polycystic ovarian syndrome, age ranging from 18-40 years, Women with PCOD Willing to have physical examinations like Weight, Height, BMI, W/H ratio, Blood Pressure, Hirsutism, Acne, Dark patches, Virilization, Ultra sonography etc.

Exclusion criteria: Women with diagnosed adrenal hyperplasia, androgen secreting neoplasm, other pituitary (acromegaly) and adrenal disorders like Cushing syndrome, Virilizing adrenal or ovarian neoplasm, hyperprolactinemia and other infertility cause, thyroid hormone related infertility, women having history of smoking, taking alcohol or tobacco chewing, any other type of gynaecologic complications except related with Polycystic ovary syndrome (PCOS) were excluded from the study.

Fasting 10ml Venous blood samples were obtained from all participants and collected it in to fluoride and plain vaccutainer. An Uniq ID number was given to each sample to hidden the identity of participants. All samples were centrifugated at 3000 RPM for a period of 10 minutes to obtained a Plasma and serum.

-Blood Glucose (FBS) measured by GOD POD method and lipid profile (S. Cholesterol, Triglyceride, HDL, LDL) measured by enzymatic colorimetric method from all samples. -VLDL was calculated by using Friedwald's formula (VLDL=TG/5).

LH and FSH was Measured by enzyme linked immune assay (ELISA) method based on electrochemilumnescence (Abbot ci4 100) from all samples.

After assessing all the values, Mean, Standard deviation of all subjects \& parameters were analysed. Statistical analysis was performed with SPSS software. Comparison between cases and with control is done by independent student's $t$ test. P-value was calculated and p-value less than 0.05 is considered as a difference of significance.

\section{Results and Discussion}

Infertility, hirsutism, and oligomenorrhea were more common among the subjects with PCOS, but there was a considerable spontaneous restitution of cyclic regularity with time. Women with PCOS were more often hysterectomized and entered menopause later compared with referents. The hormone data show a typical profile for PCOS. Compared with referents women with PCOS showed marked increase in prevalence of central obesity, higher basal serum insulin concentrations, and a higher prevalence of diabetes mellitus and hypertension. ${ }^{4}$

Table 1: Age wise distribution of participants

\begin{tabular}{|l|c|c|}
\hline \multicolumn{1}{|c|}{ Groups } & Number(n) & $\begin{array}{c}\text { Age (years) } \\
\text { Mean } \pm \text { SD }\end{array}$ \\
\hline Group 1 (Cases ) & 300 & $27 \pm 5.4$ \\
\hline Group 2 Controls) & 200 & $24.98 \pm 4.13$ \\
\hline
\end{tabular}

Table 2: Comparison of weight between cases and controls

\begin{tabular}{|l|c|c|}
\hline \multicolumn{1}{|c|}{ Groups } & Number(n) & $\begin{array}{c}\text { Weight }(\mathbf{K g}) \\
\text { Mean } \pm \text { SD }\end{array}$ \\
\hline Group 1(Cases) & 300 & $56.91 \pm 8.24$ \\
\hline Group 2(Controls) & 200 & $45.36 \pm 5.8$ \\
\hline
\end{tabular}

Table 3: Comparison of waste hip $(\mathrm{W} / \mathrm{H})$ ratio between cases and controls

\begin{tabular}{|l|l|l|}
\hline \multicolumn{1}{|c|}{ Groups } & Number(n) & $\begin{array}{c}\text { W/H ratio } \\
\text { Mean } \pm \text { SD }\end{array}$ \\
\hline Group 1(Cases ) & 300 & $0.89 \pm 0.13$ \\
\hline $\begin{array}{l}\text { Group } \\
\text { 2(Controls) }\end{array}$ & 200 & $0.79 \pm 0.0 .3$ \\
\hline
\end{tabular}

Table 4: Comparison of BMI between cases and controls

\begin{tabular}{|l|l|c|}
\hline \multicolumn{1}{|c|}{ Groups } & Number(n) & $\begin{array}{c}\text { BMI } \\
\text { Mean } \pm \text { SD }\end{array}$ \\
\hline Group 1(Cases ) & 300 & $22.70 \pm 3.73$ \\
\hline $\begin{array}{l}\text { Group } \\
\text { 2(Controls) }\end{array}$ & 200 & $17.72 \pm 2.41$ \\
\hline
\end{tabular}

Table 5: Comparison based on menstrual cycle history between cases and controls

\begin{tabular}{|c|c|c|c|c|c|}
\hline & \multicolumn{2}{|c|}{ Groups } & \multirow[t]{2}{*}{ Total } \\
\hline & & & Controls & Cases & \\
\hline \multirow[t]{3}{*}{ M.H./CYCLE } & \multirow[t]{2}{*}{$<5$} & Count & 0 & 22 & 22 \\
\hline & & $\%$ within GROUP & $0.0 \%$ & $7.3 \%$ & $4.4 \%$ \\
\hline & $5-9$ & Count & 0 & 277 & 277 \\
\hline
\end{tabular}




\begin{tabular}{|c|c|c|c|c|c|}
\hline & & $\%$ within GROUP & $0.0 \%$ & $92.3 \%$ & $55.4 \%$ \\
\hline & $>=10$ & Count & 200 & 1 & 201 \\
\hline & & $\%$ within GROUP & $100.0 \%$ & $0.3 \%$ & $40.2 \%$ \\
\hline Total & & Count & 200 & 300 & 500 \\
\hline & & $\%$ within GROUP & $100.0 \%$ & $100.0 \%$ & $100.0 \%$ \\
\hline
\end{tabular}

Table 6: Comparison of FBS and lipid profile between cases and controls

\begin{tabular}{|l|l|c|c|c|}
\hline \multicolumn{1}{|c|}{ Parameter } & Group & Number $(\mathbf{n})$ & Mean \pm SD & p-value \\
\hline \multirow{2}{*}{ FBS $(\mathrm{mg} / \mathrm{dl})$} & Cases & 300 & $106.7 \pm 19.4$ & $<0.001$ \\
\cline { 2 - 4 } & Controls & 200 & $96.12 \pm 17.03$ & \\
\hline \multirow{2}{*}{ S.choletsterol $(\mathrm{mg} / \mathrm{dl})$} & Cases & 300 & $189.1 \pm 45.47$ & \multirow{2}{*}{$<0.001$} \\
\cline { 2 - 4 } & Controls & 200 & $157.49 \pm 23.80$ & \\
\hline \multirow{2}{*}{ S.Triglyceride $(\mathrm{mg} / \mathrm{dl})$} & Cases & 300 & $160.69 \pm 36.98$ & \multirow{2}{*}{0.025} \\
\cline { 2 - 4 } & Controls & 200 & $154.62 \pm 23.42$ & \\
\hline \multirow{2}{*}{ S.HDL $(\mathrm{mg} / \mathrm{dl})$} & Cases & 300 & $40.24 \pm 6.30$ & \multirow{2}{*}{0.006} \\
\cline { 2 - 4 } & Controls & 200 & $38.66 \pm 6.25$ & \\
\hline \multirow{2}{*}{ S.LDL (mg/dl) } & Cases & 300 & $116.95 \pm 42$ & \multirow{2}{*}{$<0.001$} \\
\cline { 2 - 4 } & Controls & 200 & $87.98 \pm 22.27$ & \\
\hline \multirow{2}{*}{ S.VLDL(mg/dl) } & Cases & 300 & $32.0 \pm 7.32$ & \multirow{2}{*}{0.032} \\
\cline { 2 - 4 } & Controls & 200 & $30.84 \pm 4.72$ & \\
\hline
\end{tabular}

Table 6A: Comparison of LH and FSH level of between cases and controls

\begin{tabular}{|l|l|c|c|c|}
\hline Parameter & Group & Number $(\mathbf{n})$ & Mean \pm SD & p-value \\
\hline \multirow{2}{*}{ S.LH $(\mu \mathrm{IU} / \mathrm{ml})$} & Cases & 300 & $147.12 \pm 39.13$ & $<0.001$ \\
\cline { 2 - 4 } & Controls & 200 & $90.86 \pm 43.62$ & \\
\hline \multirow{2}{*}{ S.FSH $(\mu \mathrm{IU} / \mathrm{ml})$} & Cases & 300 & $76.42 \pm 45.67$ & $<0.001$ \\
\cline { 2 - 4 } & Controls & 200 & $22.22 \pm 17.11$ & \\
\hline
\end{tabular}

1. Comparison of the fasting basal sugar (FBS) between the two groups shows that FBS is higher $($ mean value $=106.7 \pm 19.49)$ in Cases group than Controls (mean value $=$ $96.1 \pm$ 17.0.(Table 6)

2. Comparison of the Triglyceride (TG) between two groups shows that TG is higher in cases (mean value $=160.6 \pm 36.98$ ) than Controls (mean value $=154.6 \pm 23.42$ ). Comparison of Total Cholesterol (TC) between two groups shows that Total cholesterol is higher (mean value $=189.1 \pm$ 45.47) in Cases than Controls.(Table 6)

3. Comparison of the luteinizing hormone (LH) between two groups shows that $\mathrm{LH}$ is higher (mean value $147 \pm 39$ ) in Cases than Controls (mean value $=90.8 \pm 43.6)$. (Table 6A)

4. Comparison of the follicular stimulating hormone (FSH) between two groups shows that FSH is higher (mean value $76.4 \pm 45.6$ ) in Cases than Controls (mean value $=22.2 \pm$ 17.1). (Table 6A)

Hardiman P. et al, Ricardo Azziz et al study show that polycystic ovary syndrome (PCOS) is a genetically complex endocrine disorder of women of uncertain etiology and is a common cause of anovulatory infertility, menstrual dysfunction, and hirsutism. PCOS appears to be associated with an increased risk of metabolic aberrations, including insulin resistance and hyperinsulinism, type 2 diabetes mellitus, dyslipidemia, cardiovascular disease, and endometrial carcinoma. ${ }^{4-10}$

By Hardiman P. et al, disorders of lipid metabolism (dyslipedaemia), cholesterol and triglycerides, PCOS patients show decreased removal of atherosclerosis-inducing remnants, seemingly independent of insulin resistance/Type II diabetes. Cardiovascular disease, with a meta-analysis estimation, a 2-fold risk of arterial disease for women with PCOS relative to women without PCOS, independent of BMI. ${ }^{4,11,12}$

By Hull M study, A high LH: FSH ratio was the most frequently found abnormality (raised in $68.4 \%$ of patients) followed by $\mathrm{LH}(65.8 \%)$, free Testosterone (FT, calculated from total Testosterone (T). Each of these four estimations was above the normal ranges in $25 \%$ of patients. ${ }^{13}$

In polycystic ovary Syndrome (PCOS), increased androgen production results in high levels of luteinizing hormone (LH) and low levels of follicle-stimulating hormone (FSH), so that follicles are prevented from producing a mature egg. Without egg production, the follicles swell with fluid and form into cysts. Every time an egg is trapped within the follicle, another cyst forms and the ovary swells, sometimes reaching the size of a grapefruit. Without ovulation, 
progesterone is no longer produced, whereas estrogen levels remain normal. ${ }^{14}$

The point at which FSH is necessary for follicular development in the human ovary is debated. Despite having no detectable FSH, our patient had multicystic ovaries with follicles up to $5 \mathrm{~mm}$ in diameter. ${ }^{15,16}$ Similar sized follicles have been reported in some women with FSH receptor mutations; however, those FSH receptor mutations may not be completely inactivating. These findings are in contrast to FSH $\beta$ - and FSH receptor-knockout mice, in which antral follicles are not maintained. ${ }^{17,18}$ In studies of human ovarian xenografts transplanted into the kidney capsule of immune deficient and hypogonadotrophic mice, FSH was required for the growth of follicles beyond the two-layer granulosa cell stage which is about the point at which the FSH receptor gene is first expressed in human follicles. ${ }^{19}$

\section{Conclusion}

PCOD is a very complicated endocrine disorder. Blood tests to measure hormone levels, an ultrasound to look at your reproductive organs and thorough personal and family histories should be completed before a PCOD diagnosis is confirmed. Assessing hormone levels serves two major purposes. First of all, it helps to rule out any other problems that might be causing the symptoms. Secondly, together with an ultrasound and personal and family histories, it helps gynecologist to diagnose the cases of PCOD.

\section{Acknowledgement}

We acknowledgement to whole department of biochemistry of our institute.

Conflict of Interest: None

Funding Agency: None

\section{References}

1. Garruti G, Depalo R, Vita MG, Lorusso F, Giampetruzzi F, Damato AB, Giorgino F. "Adipose tissue,metabolic syndrome and polycystic ovary syndrome: from pathophysiology to treatment."Reprod. biomed. Online, 2009;19:552-63.

2. Nardo LG, Patchava S, Laing I. "Polycystic ovary syndrome: pathophysiology, molecular aspects and clinical implications." Pan Minerva Med 2008 Dec;50(4):267-78.

3. Artini PG, Di Berardino OM, Simi G, Papini F, Ruggiero M, Monteleone P, Cela V; "Best methods for identification and treatment of PCOS.’MinervaGinecol, 2010 feb;62(1):33-48.
4. Hardiman P, Pillay OC, Atiomo W "Polycystic ovary syndrome and endometrial carcinoma.".Lancet 2003,:1810-2

5. Ricardo Azziz, Keslie S. Woods, Rosario Reyna, Timothy J. Key, Eric S. Knochenhauer and Bulent O. Yildiz. The Prevalence and Features of the Polycystic Ovary Syndrome in an Unselected Population; Volume 89(6), 110-14.

6. Hull MG Epidemiology of infertility and polycystic ovarian disease: endocrinological and demographic

studies. GynecolEndocrinol 1987:1:235-45

7. Azziz RThe evaluation and management of hirsutism. ObstetGynecol 2003 101:995-1007

8. Ovalle F, Azziz R Insulin resistance, polycystic ovary syndrome, and type 2 diabetes mellitus. FertilSteril 2002 Vol 77:1095-105

9. Wild RA 2002 Long-term health consequences of PCOS. Hum Reprod Update 8:231-41

10. Legro RS Polycystic ovary syndrome and cardiovascular disease: a premature association?Endocr Rev 2003:24:302-12

11. Hardiman P, Pillay OC, Atiomo W (). "Polycystic ovary syndrome and endometrial carcinoma". Lancet May 2003:1810-2.

12. New MI (). "Nonclassical congenital adrenal hyperplasia and the polycystic ovarian syndrome.".Annals of the New York Academy of Sciences May 1993:687:193-205

13. Hull M. G. R., Savage P. E., Bromham D. R. Anovulatory and ovulatory infertility: results with simplified management. Br. Med. J. 1982;284:1681-85

14. Hardiman P, Pillay OC, Atiomo W (). "Polycystic ovary syndrome and endometrial carcinoma.". Lancet May 2003:1810-12.

15. Gougeon, A. (Regulation of ovarian follicular development in primates: facts and hypotheses. Endocr. Rev., 1996 17,121-55

16. Aittomaki, K., Herva, R., Stenman, U-H. et al. (1996) Clinical features of primary ovarian failure caused by a point mutation in the folliclestimulating hormone receptor gene. J. Clin. Endocrinol. Metab , 81,3722-6

17. McGee, E.A. and Hsueh, A.J.W. () Initial and cyclic recruitment of ovarian follicles. Endocr. Rev., 2000: 21, 200-14.

18. Oktay, O., Newton H., Mullan J.) Development of human primordial follicles to antral stages in SCID/hpg mice stimulated with folliclestimulating hormone. Hum. Reprod. 1998:13, 1133-8.

19. Kumar, T.R., Wang, Y., Lu, N. Folliclestimulating hormone is required for ovarian follicle maturation but not male fertility. Nature Genet. , 1997:15, 201-4. 